\title{
USING ADVERSE EVENT PYRAMIDS TO ASSESS PROBABILITIES IN AIRLINE SAFETY MANAGEMENT
}

\author{
Aleksandrs Bitins ${ }^{1}{ }^{\text {(DD }}$ 0000-0001-7498-0898 \\ Juris Maklakovs ${ }^{2}$ (D) 0000-0002-1022-2016 \\ Ruta Bogdane $^{1}$ (iD 0000-0002-4385-3703 \\ Rafał Chatys $^{3}$ (iD 0000-0002-2168-286X \\ Vladimir Shestakov ${ }^{2 *}$ (iD 0000-0001-6132-500X \\ ${ }^{1}$ SmartLynx Airlines Ltd LV-1658 Riga, Latvia \\ ${ }^{2}$ Institute of Aeronautics, Riga Technical University, 1 Kalku Str., LV-1658 Riga, Latvia \\ ${ }^{3}$ Kielce University of Technology, Al. 1000-lecia Państwa Polskiego 7, 25-322 Kielce, Poland \\ *shestakov@inbox.lv
}

\begin{abstract}
This article reviews the methods of safety management using Heinrich's and Bird's pyramids. The presence of a causal relationship between pyramid levels, as a result of inconsistencies in the activities of an organization and personnel, lead to incidents, and incidents in turn lead to accidents. The existence of such a relationship makes it possible to predict the risk of "top-level" events by reducing risks at the middle and lower levels. A mathematical description of the development process of an undesired aviation event is presented, which makes it possible to evaluate the probability of the successful (or unsuccessful) completion of a transportation task. Also given is an analysis of the development of an aviation accident, based on the example of the crash of a Lufthansa A-320 aircraft on 14 September 1993 at the airport of Warsaw (Poland) while landing in adverse weather conditions.
\end{abstract}

Keywords: Airline safety management, risk analysis

Type of the work: Research Article

\section{INTRODUCTION}

The problem of ensuring safety is complex in nature, requiring a system of measures to support preventive actions to lower the number of incidents, reduce their severity, and eliminate their consequences. At the same time, safety problems in various spheres of human life have both a general solution and their own domain-specific approaches. The general solution needs to involve a multifarious concept of risk.

Risk refers to a situation with an uncertain outcome, necessarily involving the possibility of potential adverse consequences. Risks may be associated with various characteristics of processes occurring in production and transport. Since risks occur at random moments in time, they can be multidimensional and can be assessed both qualitatively and quantitatively. The concept of the probability of one event occurring when another occurs is therefore a universal measure - it is a crucial tool that allows the initial goals and strategies for solving the problems facing an enterprise to be adjusted on the basis of risk 
analysis, hazards of different natures and their mechanisms of action to be compared, potential sources of danger to be classified and ranked according to their contribution to integral risk indicators, and the causal logic of the occurrence and development of undesirable events to be explored and studied.

All of the above certainly applies to the aviation business. In ICAO documents, flight safety is defined as "a state in which the risks associated with aviation activities are reduced to an acceptable level and controlled.” [1]. The main task in maintaining the proper level of flight safety in an airline, therefore, consists in identifying risks, assessing them, and taking measures to reduce them to an acceptable level. This ICAO recommendation entered into force in 2013. Currently, each airline builds its own flight safety system based on these principles, proceeding from its own approach and relying on the experience of other enterprises, including non-aviation ones.

The purpose of this article is to present a physical and mathematical representation of the development process of an undesired aviation event, which makes it possible to evaluate the probability of the successful (unsuccessful) completion of a transportation task. This is illustrated by an examination of the development of a specific aviation accident: the crash of a Lufthansa A-320 aircraft on 14 September 1993 at the airport of Warsaw while landing in adverse weather conditions.

\section{COMMON CHARACTERISTICS OF RISKS IN THE TRANSPORT INDUSTRY}

Currently, the notion of "risk" (or the synonymous "adverse factor") has come to be widely incorporated into various areas of human activity. Risk is designated as a "major" or "minor" hazard of an adverse event occurring. The concept of risk is highly multifaceted [10,11]. It reflects a situation with an uncertain outcome, necessarily involving the possibility of potential adverse consequences. Based on this sense, risk analysis is the quantitative assessment of hazards, defined as the frequency of occurrence of one event when another occurs.

Generally, the word "risk" is most often understood as referring to potential losses, and it can also be described as the probability of obtaining some result that is different from the expected one. Risk is associated with various processes occurring in transport; it manifests itself at random times and can be multidimensional and conditional. The concept of risk is a universal quantitative measure of potential danger, which allows initial goals and strategies for solving problems to be adjusted, hazards of various nature and mechanisms of action to be compared, potential sources of danger to be classified and ranked according to their contribution to integral risk indicators, the mechanisms involved and the cause-andeffect logic of the occurrence and development of undesirable events to be investigated, the influence of various factors on the risk indicators to be studied, and the direction of risk reduction to be ensured due to the optimal management of technical and organizational-methodological factors of influence (reducing probabilities, reducing the magnitude of damage). Within the framework of the concept of risk as a hazard, depending on the possibility of formalizing the problem and the available initial information, both quantitative indicators and qualitative indicators are utilized. The latter are employed in the absence of the possibility of quantitative assessments (necessary statistics, model), and expert assessment is used to determine them.

The concept of "risk" is the most frequently used quantitative characterization of the realization of a hazard. Risk indicators as a general indicator of harm in assessing the impact on a human of various negative factors are used to determine working conditions and financial losses. Risk is the expected frequency or probability of a hazard, a function of both the probability of an event occurring and the possible consequences stemming from it. More than 200 types of risks are mentioned in the scientific literature. Currently, there is common formula for determining risk, which can be expressed as follows:

$$
R=\{N(t)\} \backslash\{Q(t)\}
$$


where $\{N(t)\}$ is the number of undesired events during time $t$ and $\{Q(t)\}$ is the total number of events during time $t$. For example, the risk of mortality from a lightning strike is $R=10^{-7} /$ year; that of mortality due to a technological disaster is $R=10^{-6}-10^{-7} /$ year; and the risk of death at work as a result of an accident or professional disease is $R=10^{-2}-10^{-4} /$ year.

In practice, when a risk arises at any facility, a certain abnormal situation arises. For a person (i.e. an operator), this involves a change in his or her psychophysiological state, whereas for a machine, it involves a change in the operational characteristics of its state. Essentially, an emergency is a safety threat. The threat can involve varying degrees of danger - from minor to fatal. The result of the occurrence of the situation will be an adverse event. An adverse event is any event that has occurred that caused harm to human health and/or material harm. Depending on the degree of danger of the previous emergency and the adverse event, it can also be of varying severity. The terms threat and danger are synonymous. If the probability of an adverse event occurring is noticeably greater than zero, it counts as a danger; if it is significantly greater than zero, it counts as a threat.

Safety is a top priority for international air transportation. At the same time, safety management has to ensure the airworthiness of aircraft, the qualifications of personnel, and aviation security as a set of measures designed to protect civil aviation from unlawful interference. To achieve these goals, airlines must set up appropriate organizational structures and functions, including identifying and controlling risk factors. However, at present no unified approach to risk management to ensure safety in an airline has been defined, and ICAO documents are not sufficiently detailed to build an effective safety management system at this level. Under these conditions, each airline seeks its own way of solving the problem, developing its own methodology and means of its implementation, based on the recommendations of international and European aviation organizations, as well as other industries. This article is devoted to the analysis of possible approaches to solving these issues that can be used in air transport.

\subsection{Adverse events in transport}

Adverse events in industry and transport may be classified in various ways. The main criterion distinguishing types of such events is the severity of the consequences and the presence of human casualties. On this basis, they may be divided into incidents and accidents: an incident involves damage to a machine, machine tool, equipment, building, structure, whereas an accident is an incident involving a quantity of fatalities. In regulatory documents and in scientific and educational literature, they are often grouped into the category of emergency incidents. Many other types of classification of adverse events are also used in the regulatory documents of specific types of transport and in the scientific and educational literature. In this article, we adopt a classification that appears in regulatory documents and aviation literature as the basic classification of adverse events [10], whereby adverse events are classified as four different possible consequences of the occurrence of risk factors:

- fatal accident (catastrophe);

- serious incident;

- serious occurrence;

- minor occurrence.

Thus, on this approach, adverse events are divided into accidents, incidents and occurrences. Accidents/incidents are associated with the death of people and/or serious material losses, while occurrences are associated only with potential or real threats, but do not end in incidents.

\subsection{The process by which an adverse event develops}

The process by which an adverse event develops is depicted in Fig. 1. It also shows how a person (operator) can intervene in the process and reduce or eliminate the consequences of risk occurrence or completely eliminate a threat to the safety of an object. 


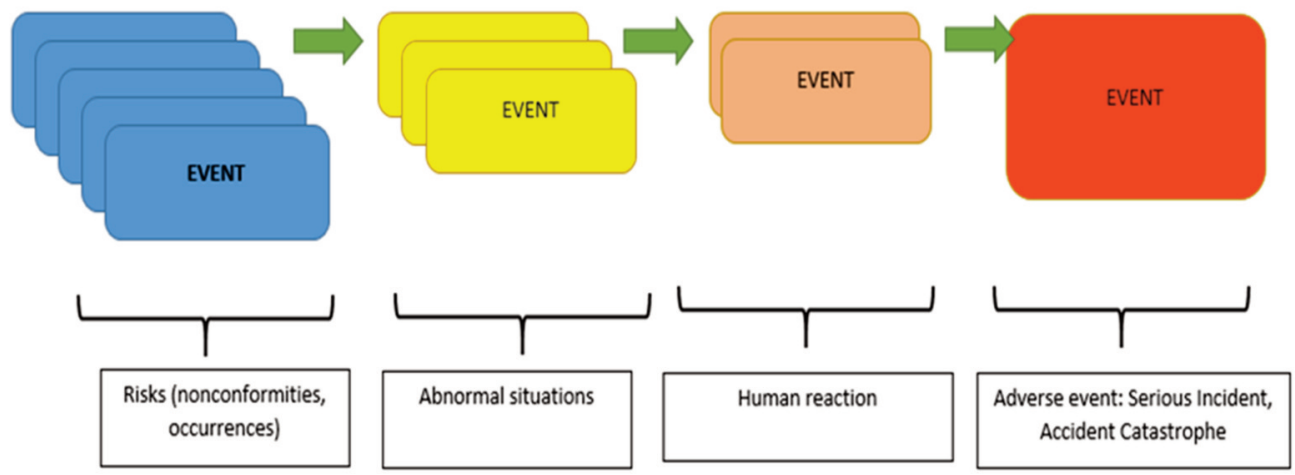

Fig. 1. The process by which an adverse event develops in transport.

\subsection{Precursor of adverse events in production and transport industries}

It has long been known in practice in the production and transport industries that, long before adverse events actually occur, certain precursors may appear. In research on the statistics of adverse events in business activity and their causes, therefore, researchers have long ago come to the conclusion that solely investigating adverse events with a large number of fatalities and material damage is not the most effective way to identify safety deficits at a particular organization - that the precursors of such events may have already existed well before the events happened, but became understandable only later. Thus, latent unsafe conditions may have existed prior to the accident. Identifying and eliminating such latent conditions requires objective and in-depth risk analysis. Therefore, a systematic approach to safety breaches is required, based on the systematic identification and elimination of these precursors. Although it is very important to fully investigate adverse events with a high quantity of fatalities, this may not be the most effective way to identify safety gaps. It is necessary to be sure that the "vital priority", which is often revealed after fatal events, is not diminished by the analysis of the rational (acceptable) risk and unsafe conditions of the object's operation. There are various models that establish the connection between the precursors of adverse events and the events themselves. One of the first to establish such a connection was Herbert William Heinrich in the field of labor protection.

\section{Heinrich's accident triangle}

Herbert William Heinrich formulated a theory of industrial accident prevention in 1931, in essence founding the scientific approach to eliminating adverse events in the workplace. Heinrich's Law (Heinrich's Triangle or Heinrich's Pyramid) states that for every major accident in the workplace, there are 29 minor injuries and 300 potentially dangerous occurrences without consequences (Fig. 2). He deduced these ratios between different types of occurrences of varying severity, outlined the domino theory of the associated sequence of events leading to an accident, distinguished between "dangerous behavior" and "dangerous conditions" as the causes of accidents, and much more. Heinrich's work has since had both supporters who further developed his framework (e.g. Bird's Triangle and the Conoco Phillips Marine Safety Pyramid) and opponents who criticized the quality of the research. However, Heinrich is correctly considered one of the pioneers of labor protection, since the statement that it is unsafe actions that lead to fatal accidents formed the basis of labor protection management systems in many industrial organizations, and later migrated to transport and to aviation. If accidents are difficult to predict and are irreversible, then unsafe behavior can be managed in an organization through educational activities and a system of rewards and fines. 


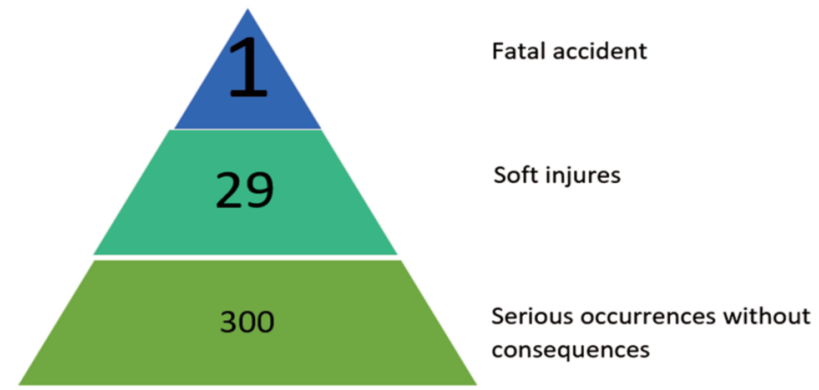

Fig. 2. Heinrich's Accident Triangle.

In 1969, the scientist Frank Bird conducted a safety study also in the industrial sphere and, through serious statistical analysis, came to the somewhat similar conclusion that in general, for every 600 in terms of the level of mildly dangerous incidents, there are 30 accidents with damage to property (accidents without seriously injured people), 10 accidents with seriously injured people, and 1 fatal accident. Thus, we arrive at the following pyramid (Fig. 3), also known as Bird's Triangle, Bird's Pyramid, or the 1:600 Rule.

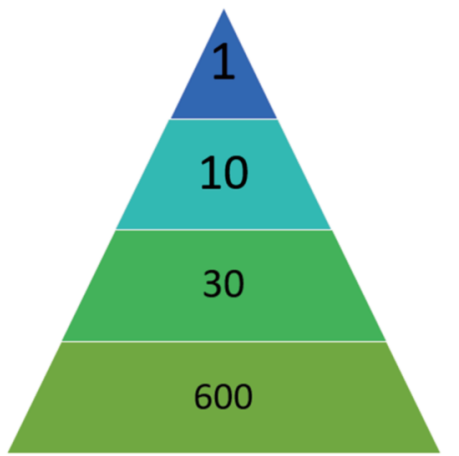

\author{
Fatal Accident \\ Injuries \\ Equipment damages \\ Violations of procedures and \\ dangerous behavior
}

Fig. 3. Bird's Accident Triangle, or the 1:600 Rule.

These pyramids illustrate well the frequency relationships between incidents with severe consequences, incidents and dangerous events [4]. The 1-10-30-600 ratio shown in Fig. 3 is an indicator of lost opportunities if investigations focus only on the relatively rare incidents of serious injury or significant damage, given that the latent factors involved in such incidents are present in hundreds of other incidents as well. An effective Safety Guide requires all personnel and management to identify and review violations before an accident occurs. Such pyramids therefore show a way to manage safety. Each manager should understand that a minor discrepancy in the activities of services and personnel, which was not properly assessed and in response to which appropriate measures were not taken, may develop into an undesired event with serious consequences.

The ideas encapsulated in the above Pyramids are based on the following principles:

1. Dividing the pyramid into three levels, we obtain the following divisions:

- upper - serious incidents (accidents, catastrophes);

- middle - incidents (events with real or potential threat);

- lower - (we may call it the "pedestal") - inconsistencies (nonconformities and occurrences) in the activities of services and personnel. 
2. The main classification criterion is the severity of the consequences of a safety violation (or the amount of damage) caused by accidents and disasters. This approach allows us not to use risk matrices when assessing risks, but to rely only on the probabilistic characteristics of the occurrence of events.

3. The presence of a stable causal relationship between the levels of Heinrich's (or Bird's) Triangle, as a result of which it can be assumed that inconsistencies in the activities of services and personnel lead to incidents, and incidents, in turn, lead to accidents and disasters. The presence of such a connection makes it possible to predict the risk of "upper level" events by planning to reduce risks at the middle and lower levels.

\section{QUANTIFICATION OF SAFETY INDICATORS}

\subsection{Using Adverse Event Pyramids to Assess Safety}

The stability of cause-and-effect relationships between the layers of the pyramid allows us to enter the coefficients of the relations $K_{I}$ - the ratio of incidents to number of events and $K_{N}$ - the ratio of inconsistencies (nonconformities) in the activities of services and personnel to number of events, in order to find the relationship between the inconsistencies on the "pedestal" level to incidents and occurrences, Fig. 4. This makes it possible to use the pyramid when building a safety management system and shift the emphasis from the traditional methods of this article, which are more related to the investigation of incidents, to systematic work to downsize the pedestal part of the system pyramid - i.e. to systematically reduce the number of inconsistencies in the activities of the organization services and their personnel.

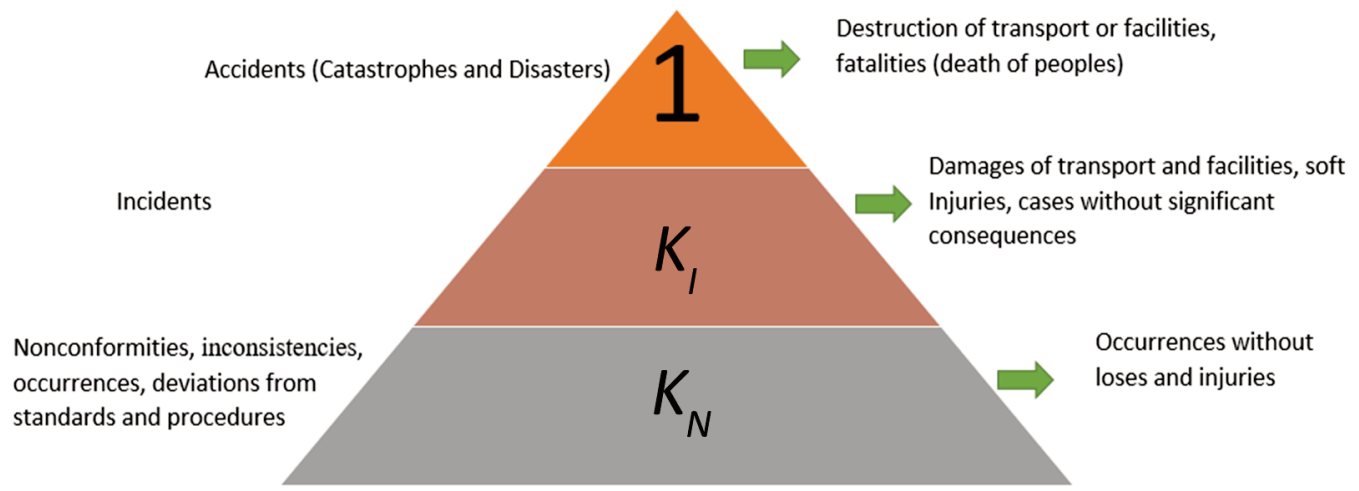

Fig. 4. Scheme for assessing the relationship between accidents $(1)$, incidents $\left(K_{I}\right)$ and inconsistencies in the activities of the enterprise $\left(K_{N}\right)$.

$K_{I}$ is the ratio of the number of incidents to events, $K_{N}$ is the ratio of the number of inconsistencies (nonconformities and occurrences) to events. The stability of resources in the Heinrich pyramid makes it possible to quantitatively characterize the level of safety at a given object as a probabilistic characteristic of the "upper level" of the pyramid - the level of incidents (catastrophes and accidents). As a basic proposal, let us use the rate of incidents per unit of time. This intensity can be estimated as a linear combination of three estimates based on the pyramid (2). The result will be a comprehensive safety indicator or safety level $K_{D L}$ :

$K_{D L}=\frac{1}{3} \lambda_{a}+\frac{1}{3} \frac{\lambda K_{I}}{K_{I}}+\frac{1}{3} \frac{\lambda K_{N}}{K_{N}}$ 
where $\lambda_{a}$ - the intensity of accidents at the organization;

$\lambda_{K I}$ - the intensity of incidents;

$\lambda_{K N}-$ the intensity of inconsistencies (nonconformities and occurrences) at organization services and their personnel;

$K_{I}$ and $K_{N}$ - ratios of the number of incidents and nonconformities to the number of adverse events during reviewed period of time. $K_{D L}$ is an incident risk assessment based on the risk assessment of all events.

The assessment should be more accurate and precise, the more accurate is the database of inconsistencies in the activities of the organization and organization personnel used in building the pyramid. It is important to note that $K_{D L}$ allows us to set numerical risk tolerances for "upper-level" events and then expand them across the rest of the levels. This safety ratio can also be used to plan and assess improvements after corrective action plans. Successful corrective action plans should exclude future incidents and nonconformities, which leads to a proportional reduction or elimination of incidents (catastrophe and accidents).

\subsection{Determination of the probability of a safe (unsafe) completion of transportation by a vehicle}

Let us present this estimate using the example of air transport [5].

\subsubsection{Abnormal situations as precursor of adverse events in flight}

Abnormal situations in flight occur when an aircraft that is in normal flight mode is exposed to one or more adverse factors (risk factors). In the literature and regulations, such situations are classified as abnormal. Abnormal situations are divided into four categories: complications of flight conditions, dangerous situations, emergency situations, and catastrophic situations [6, 7]. A combination of aircraft characteristics and psychophysiological indicators of the pilots, which differ from the normative ones, characterize abnormal situations in flight and the flight mode from the "standard" one. Based on this concept, five possible states of an aircraft in flight can be distinguished. Let us denote them by $S_{i}$, where $i=0,1,2,3$, 4: normal ("regular") flight in the absence of risk factors $-S_{0}$; complication of flight conditions $-S_{1}$; dangerous situation $-S_{2}$; emergency $-S_{3}$; catastrophic situation $-S_{4}$.

- $S_{0}$ - "normal" situation. The flight takes place under the expected operating conditions in the area of the recommended flight modes.

- $S_{1}$ - complication of flight conditions. A "condition of the aircraft in flight" characterized by a slight increase in psychophysiological load on the crew or a slight deterioration in stability and controllability or flight characteristics of the aircraft.

- $S_{2}$ - difficult situation. A "condition of the aircraft in flight" characterized by a noticeable increase in psychophysiological load on the crew or a noticeable deterioration in flight performance, stability and controllability, as well as one or several flight parameters outside the operational limits, but without reaching the limiting limits and design conditions. Preventing a difficult situation from transitioning into an emergency or catastrophic one can be ensured by timely and correct actions of the crew, including an immediate change in the plan, profile and flight mode.

- $S_{3}$ - emergency situation. A "condition of the aircraft in flight" characterized by a significant increase in psychophysiological load on the crew, deterioration in flight performance, stability and controllability and leading to the limit values and design conditions being reached (exceeded). Preventing an emergency situation from transitioning into a catastrophic one requires high professional skill on the part of the crew members.

- $\mathrm{S}_{4}$ - catastrophic situation. A "condition of the aircraft in flight" for which it is assumed that preventing the death of people is practically impossible. 
When an exceptional situation arises, that is, the aircraft does not respond appropriately to the pilots' actions to counter the consequences of the risk factor, one of the adverse events described above occurs: an incident or an aircraft accident [8].

There are various models for the development of this process [1-4] Fig. 5.

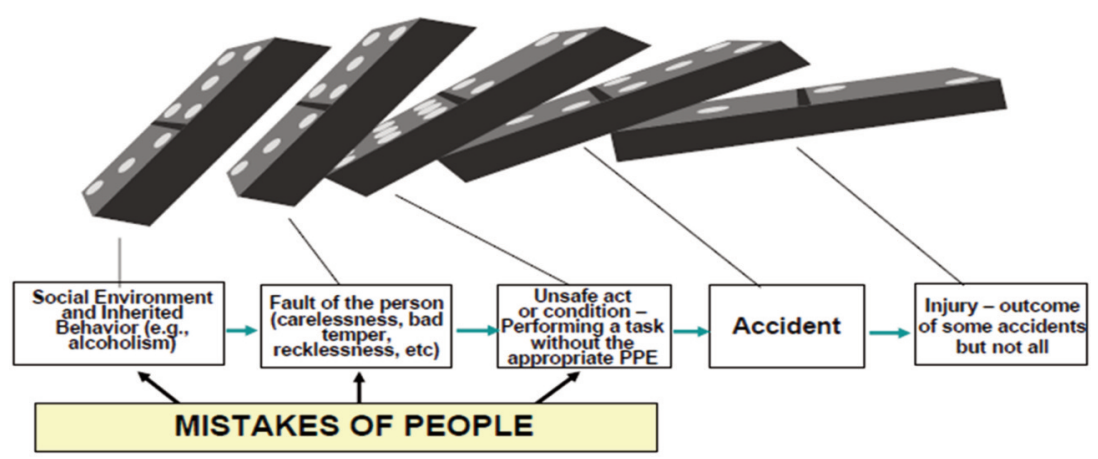

a)

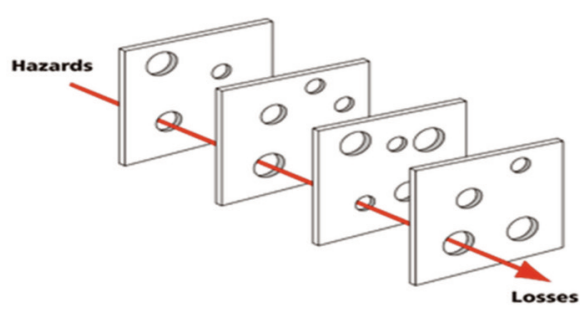

b)

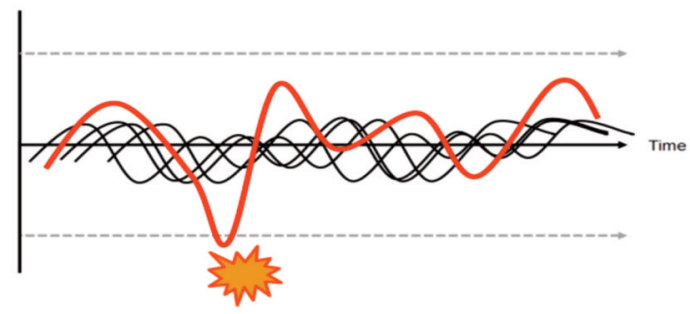

c)

Fig. 5. Types of aircraft accident development models: a) the domino model, b) the Swiss cheese model, c) the "chain reaction" model.

\subsection{Mathematical interpretation of the development of an adverse event in flight}

To calculate the probability of the safe completion of a flight, consider the "Event Tree" (Fig. 6) as a sequence of aircraft transitions in flight from one state to another [9].

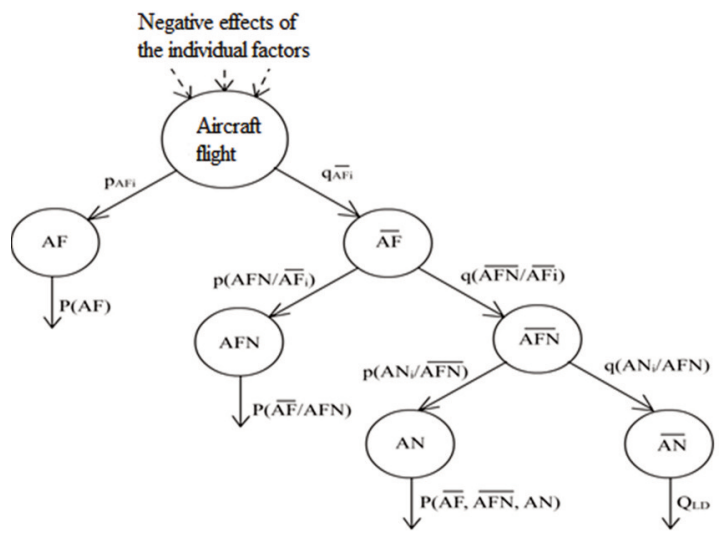

Fig. 6. Aviation incident development scheme [6]. 
Designation of the appropriate "crew - aircraft" system state:

$A F$ and $\overline{A F}$ - Crash factor not manifested/manifested

$A F N$ and $\overline{A F N}$ - Crash factor corrected/not corrected

$A N$ and $\overline{A N}$ - Flight safe ending/aviation accident

The possibilities of transitions from one condition to another are denoted by arrows (arcs). The probabilities of transition are marked on arrows. When determining the probability of successful completion of flight $P_{L D}(t)$ should consider different options for possible transitions.

1. No crash factor in flight (event $A F)$. In this case the probability $P_{L D}(t)$ will be appropriate for the probability of an accident.

$$
P_{A F}=p_{A F_{i}}
$$

2. In a flight the system may result in an emergency factor $A F$ with a probability of $q \overline{A F_{i}}$. Its appearance means only the possibility, not the inevitability of an aviation accident. At the beginning of the event, the aircraft parameters are to some extent different from those committed. When this becomes evident from information sources, the pilot will try to prevent the consequences of the factor and, above all, seek to eliminate the parameter $X_{i}$, which is bounded by the safety conditions of the flight, outside of the permissible limits $\left(\alpha \leq \alpha_{\text {perm }}, n_{y} \leq n_{y \text { perm }}, M \leq M_{\text {perm }}\right.$ ). In general, the pilot may prevent the consequences of an accident factor $\overline{A F}$ or not prevent them.

Let us presume probability of this event by $p\left(A F N / \overline{A F_{i}}\right)$ and $\left(\overline{A F N} / \overline{A F_{i}}\right)$, respectively. In the case of a favourable ending of the flight, in the event of the pilot's intervention and the consequences of the factor:

$$
P_{L D}\left\{\overline{A F_{i}} / A F N\right\}=q_{\overline{A F}} \times p\left(A F N / \overline{A F_{i}}\right)
$$

3. If, despite pilot intervention, the relevant parameters have gone beyond the permitted limits, this does not necessarily end in an aviation accident. Suppose that the effect of an incident is to exceed the permissible angle of attack and the aircraft starts to move down. In this case, the pilot, with the right actions, may prevent the aircraft from going down and prevent an accident from the aircraft. The probability of accident elimination following the departure of the determination parameter outside the permitted limits is $p\left(A N_{i} / \overline{A F N}\right)$ [6].

The probability of a safe ending of the flight after an accident and departure of the determinants outside the limits is:

$$
P_{L D}\left\{\overline{A F_{i}}, \overline{A F N}, A N_{i}\right\}=q_{\overline{A F_{i}}} \times q\left(\overline{A F N} / \overline{A F_{i}}\right) \times p\left(\overline{A N_{i}} / \overline{A F N}\right)
$$

The probability that the flight will lead to aviation accident can be expressed as:

$$
P_{L D}\left\{\overline{A F_{i}}, \overline{A F N}, \overline{A N_{i}}\right\}=Q_{L D}(t)=q_{\overline{A F_{i}}} \times q\left(\overline{A F N} / \overline{A F_{i}}\right) \times q\left(\overline{A N_{i}} / \overline{A F N}\right)
$$

So, the probability of a flight's safe conclusion is:

$$
\begin{aligned}
& P_{L D}(t)=1-Q_{L D}(t)=1-q_{\overline{A F_{i}}} \times q\left(\overline{A F N} / \overline{A F_{i}}\right) \times q\left(\overline{A N_{i}} / \overline{A F N}\right)= \\
& 1-\left(1-p_{A F_{i}}\right) \times\left\{1-\left(\overline{A F N} / \overline{A F_{i}}\right)\right\} \times\left\{1-\times\left(\overline{A N_{i}} / \overline{A F N}\right)\right\}
\end{aligned}
$$


In most cases, the notional probability of prevention of an accident in the aviation situation is $p\left(A N_{i} / \overline{A F N}\right)$. Then the probability of a flight's safe conclusion is:

$P_{L D}(t)=p_{A F_{i}}+\left(1-p_{A F_{i}}\right) \times p\left(A F N / \overline{A F_{i}}\right)$

Thus, the probability of successful completion of the flight for the i-th risk factor depends on the probability of its non-appearance in flight and the conditional probability of the pilot's recovery from the output defining parameters beyond the permissible limits. The risk level of an aviation accident in this case will be:

$Q_{L D}(t)=1-P_{L D}(t)$

The likelihood of an accident also depends on the phase of the flight of the aircraft (takeoff, cruising, landing). At various stages, various adverse factors are possible. Thus during takeoff and landing, technical factors may include failures of the chassis, mechanization, brakes etc., while adverse external effects may include icing, wind shifts, etc.; during the cruise stage, they may include failure of the conditioning system, interaction of turbulences etc. The probability value of an aircraft getting into special situations should be accounted for according to the flight phase, following the standard profile. In case of technical factors, for example, mechanisms which are working for a limited period of time (chassis, flaps etc.), the probability of functional failures should apply against work cycles.

\section{AN EXAMPLE OF A CHAIN MODEL IN THE DEVELOPMENT OF AN ADVERSE EVENT (CRASH) OF AN AIRCRAFT}

In this section we present a detailed analysis of the development of an aviation accident with an assessment of the transition of special situations from less dangerous to more dangerous with the appearance of new unsafe factors at each stage, based on the example of the crash of a Lufthansa A-320 aircraft on 14 September 1993 at the Warsaw airport (Poland) when landing in adverse weather conditions [7].

\begin{tabular}{|c|}
\hline - Windshear warning \\
\hline $\begin{array}{l}\text { - Increased speed } \\
\text { - Heavy rain }\end{array}$ \\
\hline $\begin{array}{l}\text { - Ineffective drainage system of runway } \\
\text { - Landing gear aquaplaning }\end{array}$ \\
\hline -Delay in wheel rotation \\
\hline -Spoilers (speedbrake) retraction delay \\
\hline
\end{tabular}


- Landing gear shock absorber compression sensor not swiched on

6

- Engine thrust reversers start to deploy after 9 second delay

7

$\bullet$ High speed during running

8

- Obstacles at the end of runway, pilot turn of the aircraft from runway

-Runway excursion at a speed 72 knots
- Aircraft hit left wing
- Fire started at left wing
-Accident: two fatalities, full aircraft destruction, damage to ground facilities

Fig. 7. A model of the development of an adverse event "chain reaction" during the landing of Lufthansa A-320 on 14 September 1993 at the Warsaw airport in adverse weather conditions.

The plane overran the runway and caught fire. Of the 70 people on board, two died. During the landing approach, the crew received a "wind shear" warning at the beginning of the runway. Therefore, the crew increased landing speed in accordance with Operational Manual. The landing took place in heavy rain. The drainage system of the runway did not cope with clearing it from water; as a result, a rather thick layer of water, 2-3 cm, was formed on it. After contact with the runway, the landing gear began aquaplaning. This led to a delay in the release of spoilers and the inclusion of a reverse thrust of the engines for 9 seconds (spoilers are only issued at certain wheel speeds and are used to reduce wing lift after contact with the runway). The aircraft overran the runway and as a result of damage taken it ignited. Thus, the case under consideration was the result of a whole complex configuration of unsafe factors, including environmental factors, human factors and aircraft design. Figure 7 shows the entire process of the development of an adverse event in color scheme and indicates abnormal situations at each stage of the development of the disaster. If even one element in this chain had been missing, the flight outcome could have been completely different, with less destructive consequences or even without any at all.

\section{CONCLUSIONS}

1. In practice, before an undesirable event occurs in transport operations, certain precursors appear. Therefore, investigating undesirable events involving deaths and property damage is not the most effective way to identify safety deficits. Rather, timely identification and elimination of such precursors requires an objective and in-depth risk analysis.

2. The concept of risk is a universal quantitative measure of potential hazard, allowing the initial goals and strategies for solving transport safety problems to be adjusted, hazards of various natures and 
mechanisms of action to be compared, potential sources of danger to be classified and ranked according to their contribution to integral safety indicators, and the causal logic of the occurrence and development of undesirable events to be explored and studied.

3. One of the effective methods of safety management involves the use of the Heinrich and Bird triangles. A stable causal relationship is assumed between the levels of such a pyramid, as a result of which it can be assumed that inconsistencies in the activities of services and personnel lead to incidents, and incidents lead to accidents and catastrophes. The presence of such a connection makes it possible to predict the risk of "upper level" events by planning to reduce risks at the middle and lower levels. Thus, the pyramid shows a way how to manage safety.

4. When one or more adverse factors are exposed to a transport unit that is in normal operating conditions, "abnormal" situations arise. Therefore, they have a pronounced random character due to the randomness of the impact of unsafe factors across time and space.

5. We have presented a mathematical description of the development process of an adverse event in aviation, allowing the probability of a successful or unsafe completion of a transport task (flight) to be assessed. Based on the example of the crash of a Lufthansa A-320 landing in adverse weather conditions on 14 September 1993 at Warsaw airport (Poland), we presented an analysis of the development of an aviation accident, with an assessment of the transitions of "emergency" situations from less dangerous to more dangerous, with the appearance of new unsafe factors at each stage.

\section{REFERENCES}

[1] ICAO, 2016, Annex 19 to the Convention on International Civil Aviation. Security Management, 2nd edition. Available at https://caainternational.com/wp-content/uploads/2018/05/AN19_2edpublication.pdf.

[2] Helmreich R. L., Klinect J. R. and Wilhelm J.A., 1999, "Models of threat, error, and CRM in flight operations." In Proceedings of the Tenth International Symposium on Aviation Psychology, The Ohio State University, Columbus, OH. 83-91.

[3] IATA, 2019, IOSA Standards Manual, $13^{\text {th }}$ Edition, Montreal-Geneva. ISBN 978-92-9229-916-3.

[4] Federal Aviation Administration, Department of Transportation, 2008, Aviation regulations. Part 25. Standards of airworthiness of aircraft of the transport category, Russia. Available at https://www.law.cornell.edu/cfr/text/14/part-25.

[5] William B., Johnson M. and Maddox E., 2007, "A model to explain human factors in aviation maintenance." Avionics News, 2, 1-5.

[6] Temjashovs, A., Tereshcenko, Je., Shestakov, V., Kuleshovs, N. and Koruba, Z., 2020, “Assessment of the Degree of Danger Posed by In-flight Contingencies When Exposed to Adverse Factors Affecting the Aircraft". Transport and Aerospace Engineering, 8(1), 21-29. https://doi.org/10.2478/tae-2020-0003.

[7] Burdun, E. and Shestakov, V., 2009, "Implementation of Graph-Analytical Formats for Mapping Aircraft Safety Performance Under Complex Flight Conditions Based on Modeling and Simulation Data." Transport. Aviation Transport. 31, 114-119. ISSN 1407-8015.

[8] Vaivads, A., Shestakov, V., L. Vinogradov, L., 2010, "Search and Emergency - Rescue Organization and Realization at Aviation Accidents in the Airport Responsibility Area", 4th International Conference on Scientific Aspects of Unmanned Aerial Vehicle, Kielce, Poland, May 5-7, 2010, 78-87.

[9] Shestakov, V., 2012, "Airplanes Incidents Analysis Because of Aviation Personnel and Evaluating the Effectiveness of Measures to Prevent Accident," in Problems of Maintenance of Sustainable Technological Systems: Sustainable Development of Transport. 5, 111-125. Kielce: Kielce University of Technology. ISBN 978-83-88906-74-9. 
[10] Zubkov, B. V. and Sharov, V. D., 2010, “Teoriya i praktika opredeleniya riskov v aviapredpriyatiyax pri razrabotke sistemy upravleniya bezopasnost'yu poletov" [Theory and practice of determining risks in air transport in the development of a flight safety control system], MGTU GA, 174, 18-25.

[11] Shestakov, V., Gorbachev, O., Stefański, K., 2019, "Assessment of Professionally Important Qualities Aviation Technical Staff”. AIP Conference Proceedings, 2077(1), 31-39. https://doi.org/10.1063/1.5091883.

[12] ICAO, 2018, Safety Management Manual (ICAO Doc 9859), $4^{\text {th }}$ Edition.

[13] Maklakovs, J., Tereshcenko, J. and Shestakov, V., 2019, "Risk Assessment of the Adverse Events in Air Transportation.” Transport and Aerospace Engineering, 1, 5-13. ISSN 2255-9876. https://doi.org/10.2478/tae-2019-0001.

\title{
WYKORZYSTANIE PIRAMID ZDARZEŃ NIEPOŻĄDANYCH DO OCENY PRAWDOPODOBIEŃSTWA W ZARZĄDZANIU BEZPIECZEŃSTWEM LINII LOTNICZYCH
}

\begin{abstract}
Abstrakt
W artykule dokonano przeglądu metod zarządzania bezpieczeństwem z wykorzystaniem tzw. piramid Heinricha i Birda. Zachodzenie związku przyczynowo-skutkowego pomiędzy poziomami piramidy, w wyniku niespójności w działaniach organizacji i personelu, prowadzi do incydentów, a incydenty z kolei prowadzą do wypadków. Istnienie takiego związku pozwala na przewidywanie ryzyka zdarzeń "najwyższego poziomu” poprzez ograniczanie ryzyka na poziomach średnim i niższym. Przedstawiono matematyczny opis procesu rozwoju niepożądanego zdarzenia lotniczego, który pozwala na ocenę prawdopodobieństwa pomyślnego (lub niepomyślnego) zakończenia zadania transportowego. Przedstawiono również analizę sposobu rozwoju wypadku lotniczego na przykładzie katastrofy samolotu A-320 linii Lufthansa w dniu 14 września 1993 r. na lotnisku w Warszawie podczas lądowania w niekorzystnych warunkach atmosferycznych.
\end{abstract}

Słowa kluczowe: Zarządzanie bezpieczeństwem linii lotniczych, analiza ryzyka 